\title{
Research on the logistics distribution model of RT Mart supermarket chain
}

\author{
Liu Yan ${ }^{1}$, Xie Lijie ${ }^{2}$, Zhao $\mathrm{Hu}^{3}$ \\ ${ }^{1}$ Beijing Wuzi University Logistics School, Tongzhou district, Beijing \\ ${ }^{2}$ Beijing Wuzi University Department of Graduates, Tongzhou district, \\ Beijing \\ ${ }^{3}$ Beijing Wuzi University Department of Graduates, Tongzhou district, \\ Beijing
}

\begin{abstract}
Supermarket chains as a profitable business model and organizational form is a mode of operation the world's most widely used. With the rapid development of supermarket chains in our country, the role of logistics distribution becomes more and more important. In this paper, based on the research of the existing logistics distribution mode, and analyzes the present situation of RT Mart supermarket logistics distribution mode and gives the RT Mart supermarket chain logistics distribution mode selection of reasonable Suggestions.
\end{abstract}

Keywords: Distribution mode; Supermarket chain; RT Mart

\section{Introduction}

An important support for the supermarket chain management is logistics and distribution, Operation of chain operation enterprises directly affected by the efficiency of the logistics distribution ${ }^{[1]}$. Efficient logistics distribution can reduce the chain business enterprise logistics cost, improve logistics service quality and increase the efficiency of logistics. 


\section{RT Mart supermarket chain logistics distribution situation}

\subsection{The basic situation of RT Mart supermarket distribution center}

To meet the needs of the major regional supermarket chain logistics distribution, RT Mart invested capital to construct the logistics distribution center of 70000 square meters in Suzhou. And the distribution center has high technical content. In the following three aspects: performance is particularly prominent:

First, the three-dimensional warehouse. Logistics distribution center is adopted by the two shelves combined warehouse storage systems. The storage system can improve warehouse space utilization.

Second, mechanical handling. RT Mart handling tool adopts electric pallet truck, electric car, electric pallet picking, transport vehicle. In this way to reduce the use of labor, improve efficiency, save costs.

Third, the scattered electronically. At present, more and more of the chain supermarket goods adopt Goods "scattered" operation. Using electronic tag picking system can greatly improve the efficiency of logistics distribution.

\subsection{Analysis of RT Mart chain supermarket logistics distribution mode}

(1) Distribution mode of fresh commodities

In general, the characteristic of fresh food is life activities. Fresh foods are apt to deteriorate, so fresh food is difficult to circulate. Transportation and storage of fresh food must be carried out under the condition of specific transport at low temperature. With the consumption of fresh food market continues to expand, the requirement of the advanced cold chain logistics distribution network in logistics distribution is more and more urgent. In the commodity distribution process in RT Mart supermarket chain, the rate of special food logistics self-supporting is relatively low.

(2) Household appliances distribution mode

First, store delivery: All the stores will sent order information to the logistics distribution center, after completed order goods distribution center will deliver 
them to the corresponding store. The logistics distribution of goods is mainly aimed at a variety of small household electrical appliances.

Second, customer delivery: Customer acknowledges that the purchase of home appliances in the corresponding store, the store will be responsible for the transfer of customers purchase goods order information to the system of logistics distribution center. Then the distribution center will be based on demand and other conditions to determine the goods out of warehouse. The division of logistics distribution region is according to customer order information of the different location. Then the logistics center will be responsible for the distribution of goods to the corresponding distribution location. This logistics mode is mainly for large household appliances distribution. Generally, supermarket chains tend to use the combining mode of third party logistics and self-run logistics.

(3) Commodity distribution model

RT Mart supermarket chain has many chain stores, what is more, in recent years, with the continuous expansion of the scale, the economic benefit is getting better and better. It relies on its own strength to build the logistics distribution network well. For most of the commodities distribution, RT mart adopt its own logistics distribution center to distribute corresponding products. For the logistics distribution center of RT Mart supermarket chain, the purpose is to realize profit. But for China's supermarket chains, if the supermarket chains are self-built logistics distribution center, it is bound to cause a large number of waste of resources. It is not possible to achieve the desired objective. Therefore, whether to establish their own logistics distribution center also need to combine the specific situation.

\section{Analysis of RT Mart logistics distribution problems}

\subsection{The backward logistics management concept}

RT Mart is not comprehensive enough of using the tactics and strategy. RT Mart pay little attention to the significance and function of logistics center. It is no doubt that a reasonable logistics center is very important for a chain 
enterprise $^{[2]}$. Because the market fluctuation, which makes the warehouse resources utilization rate is not high. Due to the low efficiency of logistics and warehousing, leading to further increase the cost of logistics enterprises budget.

\subsection{Technological backwardness of distribution facilities}

Some foreign companies have begun using high-tech distribution center operating mode now. In the process of the loading and unloading operations, many companies begin to use more electric vehicles, conveyors and other tools. The logistics centers tend to mechanization and automation. RT Mart supermarket's distribution center operation still relies mainly on manual operation, high-tech distribution facilities and technology and has not been fully exploited.

\subsection{Failure mechanisms of cooperation with suppliers}

RT Mart supermarket at present is to drive down the prices of the suppliers to earn the difference in order to maintain their own profit. The relationship above situation caused the RT mart and suppliers in a very nervous state. Not only vendors undertakes risk alone and supermarkets also share benefits by themselves. The relationship between enterprise and supplier partner is not closely enough.

\subsection{Distribution of goods is fragmented}

At present, the distribution average efficiency of foreign supermarket chains is $80 \%$ to $90 \%$.But the distribution efficiency of the RT Mart is only $60 \% \sim 70 \%$. Because of the market expansion, the distribution efficiency may be lower than 60\% 70\%. RT Mart warehouse utilization rate and Vehicle efficiency is low, mainly because of the vehicle always idle and the longer inventory turnover period of commodity. Moreover, the distribution scale of RT-Mart is low and the number and level of the distribution center are lower than the leading foreign chain enterprises. 


\section{3. Suggestions for RT Mart Logistics distribution mode}

\subsection{Matrix decision diagram method for RT Mart logistics distribution mode}

Through the division of management capabilities, enterprise scale, requirements on the delivery service level and distribution capacity and other aspects, we get four types of chain supermarket.

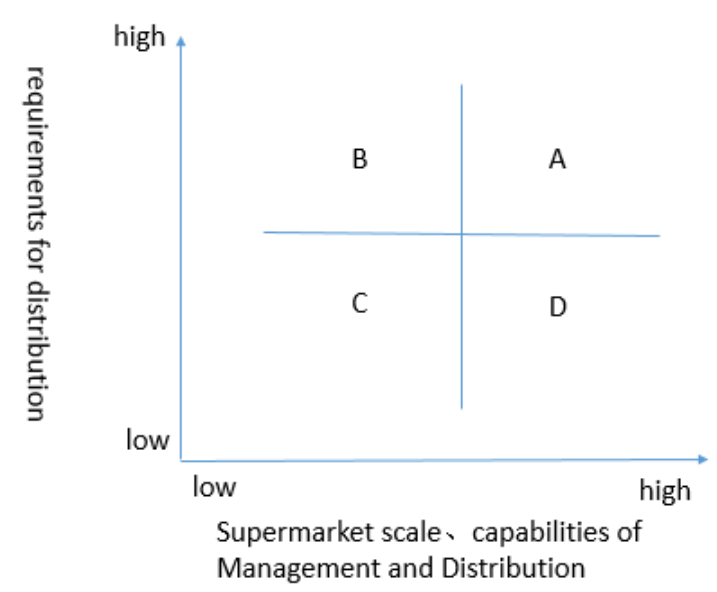

The first type (A) of supermarket chains own strong ability of distribution and operating. Such supermarket chain requires a strong distribution system. This type supermarkets are generally more successful, and the scale is large. Such as Carrefour, Wal-Mart, etc.

The second type (B) of supermarket chains although need high levels of logistics and distribution, but its operational strength is weak. Its level of logistics distribution capacity is not enough high. Such supermarkets are generally in the development of small or medium sized supermarket.

The third type (C) of supermarket chains is not high on the delivery capacity requirements. And at this stage its capacity of management is still at a low level. This type of chain supermarket is mostly just to establish or its development time is relatively short and its scale is small.

The forth type (D) of supermarket chains is the combination of supermarket chain management and modern logistics. This kind of supermarket has high- 
quality logistics talents, strong distribution capabilities and advanced distribution equipment. But the distribution business does not occupy the main status in the supermarket development strategy. This kind of supermarket is suitable to take advantage of its operation scale and its high level of management ability to get more profits.

RT Mart belongs to the first type. Distribution center is important to the development of supermarket chains, but must choose the appropriate form ${ }^{[3]}$. The most suitable model for its distribution is combine self-built logistics distribution center and a variety of other distribution modes.

\subsection{The detailed proposals for RT Mart distribution mode}

Based on the improved scheme of the RT Mart distribution model. This paper put forward the improvement proposals of the RT Mart selfdistribution mode, the supplier distribution mode, third party logistics distribution mode.

(1)Strategy to improve self-distribution mode

RT Mart should be change its self-distribution center which as a cost center of enterprise former to the enterprise profit center. And gradually participate in the market competition, transform providing simple logistics service department to the integration of logistics resources department. Take advantage of their own superiority to develop the logistics market. Change the selfdistribution center to the third party logistics enterprises to provide logistics services. Put a cost center into a profit center which will become a new profit source of RT Mart supermarket chain.

(2)Strategy to improve the supplier distribution mode

Due to the growing number of RT Mart supermarket chain stores, the expansion of the individual shops scale, the deficiency of only use the supplier delivery mode will prominent. RT Mart supermarket chains can according to the different kinds of goods to have different treatment methods. It can also according to the characteristics of goods distribution and quantity, combine 
the directly and indirectly distribution model. It can not only improve the delivery service level, but also can save the cost of distribution service.

Fresh and frozen foods must have the strict health and insulation measures in the transport and storage process .It also need special transportation and warehousing equipment ${ }^{[4]}$. For the requirements of special distribution or the provisions of the short delivery time of fresh agricultural products, RT Mart supermarket can use supplier distribution model. Suppliers will be required to deliver fresh products directly to supermarkets. This method will shortens the distribution link, and can ensure the quality of fresh products. It not only can save the cost of distribution and also can improve the distribution service level.

(3)Strategy to improve the third party logistics distribution mode.

The third-party distribution with certain scale and specialized in the distribution of third-party distribution enterprise, using its own assets and business forms, and the mode of delivery services to the users in a defined area ${ }^{[5]}$.The distribution of RT Mart supermarket chain stores is relatively dispersed, and there are a lot of store types and a large amount of daily distributions. Even if own its self-built distribution center, advanced management system and perfect distribution system, but it still need to work with third party logistics company in some logistics business to complete its distribution. Especially in the multi-frequency, short-distance of the city regional distribution, outsourcing have more obvious advantages.

Through the transformation of the third party distribution mode RT Mart supermarket can concentrate on the core business operations. RT Mart can enjoy the high level of distribution service, lower distribution costs and more professional.

\section{Conclusion}

The concept for the supermarket chain is still in the early stages of development in China. In summary, with the gradual deepening study of distribution theory of logistics in our country, the constantly using of new technology and new equipment, the improving level 
of enterprise management, logistics and distribution system of chain enterprises will become a huge driving force to improve the effectiveness and efficiency chain enterprises in China.

\section{References}

[1]Ning Zhang, Analysis rational distribution mode of China's retail supermarket chain [J]. Distribution of goods,2011.

[2]Ning Wang, Research on the problems and Countermeasures of supermarket chain logistics distribution [J]. Management of the world. 2008.

[3]Xiaohua Li, Discussion on the problems and Countermeasures of logistics distribution mode of supermarket chain $[\mathrm{J}]$, Distribution of goods.2009.

[4] Shuangbo Yan, Analysis of Chinese supermarket chain logistics distribution mode [J].Logistics technology.2010.

[5]Fangtao Jiang, Yiting Gao, Status and Optimization Strategies Based Supermarket Chain of the Supply Chain and Distribution Mode[J],Scientific Research.2012. 